\title{
(D) ESCOLAR
}

\section{(D) SCHOOL}

\section{(D) ESCUELA}

\author{
Vinicius Leite Reis ${ }^{1}$ \\ Bruno Costa Lima Rossato ${ }^{2}$
}

\section{RESUMO}

Os processos de escolarização são hoje um direito defendido na ONU que aponta ser esta a solução possível para o enfrentamento da intolerância e do discurso de ódio. Entretanto, segundo a própria ONU, em 2019, 262 milhões de crianças e jovens ainda estão fora das redes de ensino. O documentário "(D)Escolar" buscou responder, a partir da inquietação de seus realizadores, a seguinte questão: para que serve a escola? Em um mundo ainda hegemonicamente regido por uma heterocisnorma branca, como sobrevivem os "diferentes" pensando na perspectiva de Deleuze, a diferença enquanto potência, afirmação e expansão da vida - os que não se enquadram nos discursos heterocentrados (PRECIADO, 2013), os que perturbam a regra geral, os dissidentes? Corpos dissidentes de gênero, raça e sexualidades habitam e, em alguns casos, sobrevivem à escola. Outros, para além da sobrevivência, quando não alijados pelo sistema educacional, aprofundam-se ainda mais nesta questão, problematizando e ressignificando as suas próprias experiências nas/com as escolas. A memória de nossos interlocutores, ponto de partida desta jornada, foi intencionalmente fabulada imageticamente no documentário para delatar a importância de tais processos nos 'espaçostempos' de (re)criação da própria experiência escolar e de nossas (re)existências. Vidas que merecem ser vivivas (BUTLER, 2018) 'dentrofora' das escolas.

PALAVRAS-CHAVE: Escola; Corpos; Gênero e Sexualidade; Cotidianos; Audiovisualidades.

\section{ABSTRACT}

Schooling processes are now a right defended at the UN, which points out that this is the possible solution to face intolerance and hate speech. However, according to the UN itself, in 2019, 262 million children and young people are still out of school. The documentary "(D) School" sought to answer, from the concern of its directors, the following question: what is the school for? In a world that is still hegemonically governed by a white heterocisnormativism, how do the "different" - thinking in Deleuze's perspective, difference as a power, affirmation and expansion of life - those who do not fit into the heterocentric discourses (PRECIADO, 2013),

Submetido em: 08/03/2020 - Aceito em: 01/04/2020 - Publicado em: 29/04/2020

${ }^{1}$ E-mail: viniciusreiswork@gmail.com / Instituição - País: Universidade do Estado do Rio de Janeiro - Brasil / Formação e instituição: Doutorando em Educação pela UERJ.

${ }^{2}$ E-mail: rossatbruno@yahoo.com.br / Instituição - País: Fundação Cecierj - Brasil / Formação e instituição: Mestre em Educação pela UERJ. 


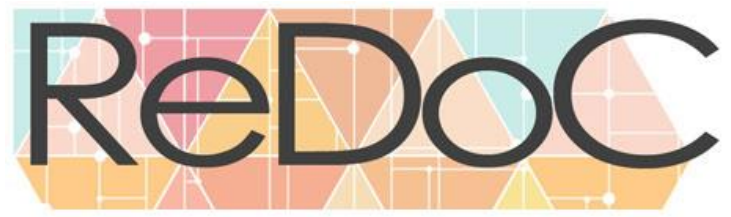

Revista Docência e Cibercultura

who disturbs the general rule, the dissidents, survive? Dissenting bodies of gender, race and sexuality inhabit and, in some cases, survive at school. Others, in addition to survival, when not excluded by the educational system, delve even further into this issue, problematizing and reframing their own experiences in/with schools. The memory of our interlocutors, the starting point of this journey, was intentionally imaged in the documentary to denounce the importance of such processes in the 'spacestimes' of (re)creating our own school experiences and our (re)existences. Lives that deserve to be lived (BUTLER, 2018) 'insideoutside' the schools.

KEYWORDS: School. Bodies. Gender and Sexuality. Daily life. Audiovisualities.

\section{RESUMEN}

Los procesos de escolarización son hoy un derecho defendido en la ONU que pretende ser la posible solución para hacer frente a la intolerancia y la incitación al odio. Sin embargo, según la propia ONU, en 2019, 262 millones de niños y jóvenes siguen estando fuera de las redes educativas. El documental "(D)Escuela" trató de responder, desde la inquietud de sus directores, a la siguiente pregunta: ¿para qué sirve la escuela? En un mundo todavía hegemónicamente gobernado por un heterocisnormativismo blanco, ¿cómo sobreviven los "diferentes" pensando desde la perspectiva de Deleuze, la diferencia como poder, afirmación y expansión de la vida aquellos que no encajan en los discursos heterocéntricos (PRECIADO, 2013), aquellos que perturban la regla general, los disidentes? Los cuerpos disidentes de género, raza y sexualidades habitan y, en algunos casos, sobreviven a la escuela. Otros, además de la supervivencia, cuando no son abordados por el sistema educativo, profundizan aún más en este tema, problematizando y resignando sus propias experiencias en las escuelas. La memoria de nuestros interlocutores, el punto de partida de este viaje, fue intencionalmente fotografiado en el documental para denunciar la importancia de tales procesos en los 'spaciostiempos' de (re)creación de nuestra propia experiencia escolar y nuestras (re)existencias. Vidas que merecen ser vividas (BUTLER, 2018) 'dentrofuera' de las escuelas.

PALABRAS CLAVE: Escuela. Cuerpos. Género y Sexualidad. La vida cotidiana. Audiovisualidades.

\section{REFERÊNCIAS}

BRASIL. LDB - Lei de Diretrizes e Bases da Educacional. Lei 9394/96 BRASIL.

BUTLER, Judith. Quadros de guerra: quando a vida é passível de luto?. Rio de Janeiro: Civilização Brasileira, 2018.

DELEUZE, Gilles. A imagem-tempo. São Paulo: Brasiliense, 1985.

LOURO, Guacira. Gênero e sexualidade: pedagogias contemporâneas. 2008. Disponível em: <http://www.scielo.br/pdf/pp/v19n2/a03v19n2.pdf $>$. Acesso em: 1 jun. 2015.

LOURO, Guacira. Pedagogias da Sexualidade. In Guacira Lopes Louro (org.), O Corpo Educado. 3a ed. Belo Horizonte: Autêntica Editora, 2013. p. 21-23. 


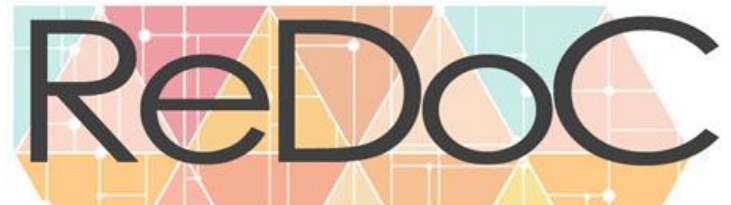

\section{Revista Docência e Cibercultura}

ONU. Em dia internacional, ONU ressalta que educação é essencial para combater intolerância e discurso de ódio. Disponível em: < https://nacoesunidas.org/em-diainternacional-onu-ressalta-que-educacao-e-essencial-para-combater-intolerancia-e-discursode-odio/ >. Acesso em: 6 abr. 2020.

PRECIADO, Beatriz. Manifesto Contrassexual: práticas subversivas de identidade sexual. São Paulo: n-1 Edições, 2014.

SCOTT, Joan Wallach. Gênero: uma categoria útil de análise histórica. Educação e Realidade, Porto Alegre, v. 20, n. 2, p. 71-99, jul./dez. 1995. Disponível em:

<https://www.seer.ufrgs.br/educacaoerealidade/article/viewFile/71721/40667>. Acesso em: 8 jun. 2015.

SOARES, Conceição. Pesquisas com os Cotidianos: devir-filosofia e devir-arte na ciência. Educação \& Realidade, Porto Alegre, v. 38, n. 3, p. 731-745, jul./set. 2013.

\section{APÊNDICE}

Link com o documentário na íntegra: https://www.youtube.com/watch?v=PJ4YQYeON7c

\section{Agradecimentos}

À nossa orientadora: Conceição Soares; ao professor Fernando Pocahy; aos participantes de (D)escolar e aos colegas que nos ajudaram com as discussões e que possibilitaram a realização deste documentário. 